\title{
A New Look At the Origin of the Immune System and New Immune Theory of Aging: Lymphocyte Regulation of Cellular Growth of Somatic Tissues: (History and Modern Concepts)
}

\author{
Vitaly I Dontsov*1,2 \\ ${ }^{1}$ Russian Academy of Sciences, Moscow, Russia \\ ${ }^{2}$ Sechenov First Moscow State Medical University, Russia
}

Received: November 14, 2017; Published: November 28, 2017

*Corresponding author: Vitaly I Dontsov, Institute for Systems Analysis, Federal Research Center "Computer Science and Control", Russian Academy of Sciences, 117312 Moscow, Russia

\begin{abstract}
Specialized cell populations should exist to carry out intercellular regulation of the growth of various types somatic tissues ("cellular hyper cycle"). Based on the data of immunology and cell biology, it is suggested that such a system should be represented by specialized T-lymphoid cells. The function of the regulation of growth of various types of somatic tissues may be more primary in phylogenies in the formation of the immune system (new theory of the origin of the immune system). The age-related immune decrease in the function of such regulatory cells may be the main mechanism of aging of the organism's self-renewing somatic tissues and may determine an age-related decrease in the growth potential of tissues of an aged organism (new immune theory of aging).
\end{abstract}

Keywords: Cell Growth Regulation; Immunity; Theory of Immunity; Aging; Theory of Aging

\section{Introduction}

The problem of regulating cell division and cell growth is one of the most fundamental problems of both theory and practice of contemporary biology and medicine. Modern theories of aging suggest also a close relationship of aging and the processes of growth and development, also consider the age-related decrease in cellular self-renewal of tissues due to their decreased tissues growth potential [1-4]. The most important level of regulation of cell growth is the interaction between growing cell populations, in order the unity of the whole organism. To describe this process, we have proposed a theory of self-organizing "cellular hyper cycle" based on the general theory of hyper cycle [5]. "Hyper cycle" in general is defined as "a concept of intrinsic self-organization that determines the integration and coordinated evolution of a system of functionally related self-replicating units" [6]. The hyper cycle theory is based on the evident inevitability of the generation during evolution of higher order regulatory relations between selfreplicating units and systems of lower order (e.g., between cells or cell populations), which form a new unified super system of a higher level. In terms of immunology and theories of "regulatory nets," this can be presented as positive selection specific clones, e.g., lymphocytes, during lymphocytes-organ interactions.
Here we briefly set out our main ideas about that:

i. Part of immune cells directly affect cellular growth of somatic cells of different types,

ii. This function is primary for the immune system and defines the primary development of regulatory cells of the immune system (new theory of the origin of the immune system),

iii. Age-related deficiency of these lymphocytes leads to a reduction of cellular growth of somatic tissues and determines tissue degeneration during aging (new immune theory of aging).

\section{T-Lymphocytes as Regulators of Somatic Cell Growth}

The importance of lymphocytes for morphostasis and regeneration processes has long been known, even before the formation of modern immunology $[7,8]$, as a stimulating effect of immuno-tropic agents. Both theoretical concepts and experimental data clearly indicate that the main role in regulation of somatic cell growth belongs to T-lymphocytes-regulators (helpers and suppressors), namely, to their nearest precursors (presumably, 
nonspecific cells-regulators of somatic cell growth - CRP) and to T-cells, which participate in the "syngenic mixed lymphocyte culture" (sMLC), and react to own cells of organism, unlike immune cells, which react to "alien" (for the specific CRP). Funds on regeneration processes [9]. The greatest attention was paid to studies concerned with the lymphocyte transfer of "regeneration information": lymphocytes taken from animals with regenerating tissue of any type and transferred to intact syngenic animals were found to induce mytoses and cell growth of the appropriate type of tissue [10-12].

The transfer of the hyper plastic reaction by lymphocytes is possible for any tissue and any process, e.g., isoproterenol-induced hypertrophy of the salivary gland of rodents, functional heart hyperplasia etc. [13-15]. It was shown also that signs of bone tissue growth-osteoporosis are corrected by transfer of lymphocytes from healthy animals; moreover, parathyroid hormone, which is specific for osteoblast, produces the effect through T-lymphocytes, which have receptors to this hormone unlike the osteoblast [16]. The regulation of fibroblast proliferation by T-lymphocytes, including the release of fibroblast-specific lymphokines, is well known. General growth inhibition, e.g., dwarfism in mice, can be prevented by the transfer of lymphocytes from healthy animals; and T-lymphocytes have receptors to the growth hormone and their number increases in the period of the animals' growth. There is a known paradox of "nude" mice, which contradicts the theory of tumor supervision (tumor supervision was thought to be the main evolutionary factor in lymphoid system development): the incidence of spontaneous and induced tumors in thymus-free mice is decreased rather than increased; moreover, the transfer of lymphocytes from normal mice restored the usual incidence of tumors in them; the decreased regeneration and tissue renewal (the dystrophy syndrome) in these animals cannot be explained only by decreased immunity and bacterial infection $[17,18]$. The "graft-versus-host" reaction leading to the inactivation of the host's own lymphocytes are accompanied by typical "nonimmune" symptoms a decrease in the induced regeneration, tissue degeneration, etc.

Facts are known of cases where lymphocytes stimulate and inhibit tumor growth, and these effects are not reduced to the typical "killer" or other purely immune phenomena [19,20]. Thus, lymphocytes are involved in the objectives a number of processes of regulation of cellular growth of different types of somatic cells and may not only be responsible for the immune processes of defense against infection or rejection of "alien" and the tumor tissue.

\section{New theory of the Origin of the Immune system}

The system of T-cell-regulators is much more complex than the systems of T- and B-effectors of immunity, and moreover, T-cells of the immune system recognize a foreign antigen in a complex with antigens of the major histocompatibility complex. The science of immunology presents thorough studies and detailed descriptions of the so-called "Syngenic Mixed Lymphocyte Culture" (sMLC), when T-cells, mainly of the T-helper and T-suppressor type, show a vigorous proliferation in response to the organism's own cells, including nonimmune ones; these are "surplus" cells in classical immunology and they can be removed by antisera without changes in the ordinary immune reactions $[13,21,22]$.

Therefore, we have suggested that the function o regulation of cell growth of somatic cells is phylogenetically more ancient and more important, then immunity itself. T- And B- effectors of immunity are phylogenetically younger [5,23-26]. In this case, the immune system is part of more general and complex system - of cell Growth Regulation System (CGRS):

i. A special system regulating somatic tissue growth (CGRS) must exist on the intercellular level, which originated, developed, and became complicated very early during evolution;

ii. The CGRS which include certain populations of T-lymphocytes (for contemporary mammals) are units of this system;

iii. Other types of cells can also form units of this system, and this permits us from following its development during evolution (first and foremost, these are macrophages and large granular lymphocytes);

iv. This system mediates many regulatory influences of hierarchically higher systems (e.g., hormonal influences);

v. During evolution, it necessary to regulate cell growth in the multicellular organism and not supervise tumors that caused a generation of the complicated T-lymphoid system, which is considered in immunology to be a regulatory system only for immunocytes:

vi. CGRS can be isolated and studied, their activity can be influenced, and they can be used to obtain specific and nonspecific regulatory factors, which affect various physiological and pathological processes;

vii. The CGRS is a special system separate from the immune system of the organism and responsible for more general and important tasks than the immune system;

viii. The immune system can be considered to be a specialized part of these system.

This function (somatic cell growth regulation) is primary for the immune system and defines the primary development of regulatory cells of the immune system in phylogenesis (new theory of the origin of the immune system in phylogenesis).

\section{A new immune-Regulatory theory of Aging}

After the appearance of the immune theory of formulated aging by $F$. Bernet etc., functions of the immune system during aging were comprehensively studied and their definite relation to the aging process was shown: age-related progressive atrophy of the thymus and lymphoid tissue as a whole, a decrease in expected lifetime with a decrease in the number of circulating T-lymphocytes, the similarity of senile changes and the consequences of early thymectomy and other immuno-deficiencies, immune disorders, and damaged expression of histocompatibility antigens in progeria, 
etc. Age-related changes are found in all functions of the immune system, especially those of the immune T-system: atrophy of the thymus, spleen and lymph nodes; a decreased number of peripheral T-cells and increased number of immature lymphocytes due to delay in their differentiation; a decreased number of T-cell precursors; a pronounced decrease in the production of thymus hormones associated with the activation of T-suppressor mechanisms and nonspecific T-helpers and T-suppressors to lead to the release of autoimmune processes; a decreased variety of lymphocyte antigen decreased production of interleukin- 2 by T-helpers pronounced decrease in lymphocyte activation by organism's own cells, i.e., a decrease in syngeneic lymphocyte culture; decreased anti-tumor resistance of the organism etc.

However, attempts to theoretical link two processes: agerelated increased lymphoid dystrophy all decreased self-renewal of other tissues, which is the main mechanism of aging in selfrenewing tissues have failed. This age-related decrease in selfrenewal of varies tissues is known to be accompanied by the development of a generalized G1/S block of proliferation: the cells prepared for proliferation is increased, but they are not stimulated for proliferation-there is a lack of growth-stimulating external factors. However, the reason for this block is well known in immunology for lymphocyte-effectors of senile animals; produced by an imbalance in the functions of T-lymphocyte-regulators. This is manifested by a reduction of the total number of T-regulators and an increased fraction of T-inhibitors. These data, along with the known sharply decreased SMLC in senility, correlate with above-mentioned concepts of the CGRS existence in organism. We have proposed a new lymphoid theory aging: a decrease in cell renewal (physiological regeneration) during aging is preceded by degeneration of the thymus and T-lymphocytes of CGRS; were proposed the immune theory of aging [23-26]. It is also known also that symptoms of ageing can be transferred to syngeneic transfer of lymphocytes from old mice [27]. Effects on thymus mediated by through the pituitary gland and the hypothalamus [28]. Age-related changes of the thymus could be reversed by transplantation of the hypothalamus from young mice to old animals, accompanied by the symptoms of their rejuvenation [29]. This is consistent with the known immune theory of aging develops and clarifies the specific mechanism of the influence of lymphocytes on tissue ageing [3031].

With regard to significance of the decreased cell growth potential of somatic tissues in the aging process of the multi-cellular organisms, a new immune theory of aging has been developed, which emphasizes the important role of age-related deficiency of the lymphocyte-dependent regulation of somatic tissue growth during aging: age-related deficiency of lymphocyte-dependent regulation of somatic tissue growth is a crucial mechanism of aging in multi-cellular organisms, that determines the decrease of selfrenewal and growth of tissues in old age and therefore age-related tissues degeneration $[25,26]$ :

a) A decrease in the self-renewal of cells is a leading mechanism somatic tissue aging. b) The decrease of cell growth of somatic tissues during aging is determinated by changes in the system of lymphoid regulation of somatic cell proliferation.

c) The essence of this changes in the CGRS in senility is an increase in the fraction of CGRS inhibitors and an absolute decrease in total number of CGRS.

d) The disrupted ratio between the stimulating and inhibiting types of CGRS results in a decreased rate of somatic cell passage from G1 phase and generation of the G1/S block in tissues of aged animals.

e) The declining proliferative activity somatic tissue cells increases the "aged" cell fraction and "senile" changes are caused by the manifestation normal properties of such cells with a prolonged life time, which are in a permanent state of differentiation.

f) Since there are continuous processes of cell renovation going on in tissues, processes of adaptation, hypertrophy etc. take place along with aging processes.

g) Change in the CGRS result from the continued influence of regulators, which limit the growth of the organism after growth termination, with the involvement of the hypothalamic - pituitary system and thymus.

Thus, the function of T-lymphocytes is suggested decrease sharply during aging due to changes in the organism's regulatory systems. We have discovered a variety of experimental evidence and have shown that it is possible to reactivate and rapidly regenerate the growth potential of somatic cells under the influence of the immunity and to reverse the symptoms of aging in the experiment $[32,33]$. Thus, the proposed new immune-age theory is not only of theoretical interest but also makes it possible to use the whole potential of immuno-pharmacology to counteract one of the crucial mechanisms of aging: the age-related decrease in cell self-renewal in the multi-cellular organisms, including mammals and humans.

\section{Conclusion}

Based on the experimental data of immunology and cell biology, we suggest that the cell growth regulation system includes specialized T-cells of stimulating and inhibiting populations, react to the organisms own growing cells. Part of immune cells directly affects cellular growth of somatic cells of different types; this function is primary for the immune system and defines the primary development of regulatory cells of the immune system (new theory of the origin of the immune system). Age-related deficiency of these lymphocytes leads to a reduction of cellular growth of somatic tissues and determines tissue degeneration during aging (new immune theory of aging). The age-related decrease in the function of such T-regulating cells may be a crucial mechanism of aging-the organism's self-renewing somatic tissues.

\section{References}

1. Atwood C, Bowen R (2011) The reproductive-cell cycle theory of aging: an update. Exp Gerontol 46(2-3): 100-107. 
2. Dontsov V, Krut ko V (2012) General system theory of aging. Sistemnyjy analis i upravlenie v biomeditsinskih sistemah 11(3): 657-663.

3. Khokhlov A (2013) Impairment of regeneration in aging: appropriateness or stochastics? Biogerontology 14(6): 703-708.

4. Walker R (2011) Developmental theory of aging revisited: focus on causal and mechanistic links between development and senescence. Rejuvenation Res 14(4): 429-436.

5. Dontsov V (1986) Theoretical prerequisites for an experimental corroboration of the existence of a specialized cellular system in control of multicellular organism tissue proliferation. Journal of hygiene, epidemiology, microbiology, and immunology 31(2): 209-217.

6. Eigen M, Schuster P (1977) The hyper cycle. A principle of natural selforganization. Part A: Emergence of the hyper cycle. Naturwissenschaften 64(11): 541-565.

7. Burwell R (1963) The role of lymphoid tissue in morphostasis. Lancet 13(2): 69-74.

8. Davies A, Leuchars E, Doak S, Cross A (1964) Regeneration in relation to the lymphoid system. Nature 14(201): 1097-1101.

9. Giełdanowski J (1983) Immunomodulatory drugs as the stimulators of proliferative process. Arch immunol ther exp (Warsz) 31(3): 345-348.

10. Babaeva A (1995) Past, present and future problems of regulation of lymphoid non-lymphoid cells. Bjulleten' jeksperimental'noj biologii i mediciny 9: 230-234.

11. Shilova L, Poltorakin V, Suslova A (1982) The effect of spleen lymphocytes of donors treated with carbon tetrachloride, on the mitotic activity of the liver and the production of alpha-fetoprotein from syngeneic mice. Bjulleten' jeksperimental'noj biologii i mediciny 93(6): 99-101.

12. Timoshevich T, Kharlova G, Yudina N (1984) Regenerative transmission of information by lymphocytes of rats with extensive bowel resection. Bjulleten' jeksperimental'noj biologii i mediciny 3: 352-355.

13. Dontsov V (1987) Isoproterenol-induced lymphocyte-dependent hyperplasia salivary glands in mice-a possible analogue of syngeneic mixed lymphocyte culture in vivo. Bjulleten' jeksperimental' noj biologii i mediciny 11: 618-620.

14. Nesterenko V (1984) A concept of immune regulation of somatic cell differentiation. J theor boil 107(3): 443-456.

15. Svet-Moldavsky G, Shkhvatsabaya I, Zinser S (1974) A study of passive transfer of lymphoid cells compensatory myocardial hypertrophy. Doklady akademii nauk SSSR 218(4): 246-249.

16. Schneider G, Relbsom M (1984) Immunological competence in osteopetrotic rets. Immunology 167: 318-324.

17. Rygaard J, Povlsen C (1974) The absence of spontaneous tumors in nude mice. Proc $1^{\text {st }}$ Int Works on Nude Mice Stuttgart 293-296.
18. Wortis H (1974) Immunological studes of the nude mice. Contemp Top Immunobiol 3: 243-263.

19. Dontsov V (1989) The Influence of lymphocytes on the growth of transplantable adenocarcinoma of the colon in mice. Jeksperimental'naja onkologija 11(5): 48-51.

20. Ponzio N (1983) Similarities between the syngenic mixed lymphocyte response and lymphoma-induced $\mathrm{T}$ cell proliferation in SJL/J mice. Behring Inst Mitt 72: 28-36.

21. Bryson J, Jones A, Caywood B, Kaplan A (1990) In vivo regulation of the murine syngeneic mixed lymphocyte reaction. Cell Immunol 129(1): 138-150.

22. Kimura S, Fukai T, Morisaki I, Daikoku H, Hamada S (1997) Senescencerelated change in autologous mixed-lymphocyte reaction in senescenceaccelerated mice. Mech Ageing Dev 99(1): 19-32.

23. Dontsov V (1989) Regulation of lymphocyte cell proliferation-an alternative theory antitumor supervision? Immunologija 5: 94-96.

24. Dontsov V (1990) Self-organization proliferating cell systems: the basis of interaction, functioning and evolution. Fiziologija cheloveka (4): 147157.

25. Dontsov V (1998) Lymphocyte regulation of cellular growth of somatic tissues and a new immune theory of aging. Fiziologija cheloveka 24(1): 82-86.

26. Dontsov V (2011) New immune theory of aging. Lambert Academic Publishing, Russian, pp. 114.

27. Babaeva A, Zuev V (2007) Deferment of the signs of aging in young mice by lymphocytes from old donors. Bjulleten' jeksperimental'noj biologii i mediciny 144: 89-90.

28. Harrison D, Archer J, Astie C (1982) The effect of hypop hysectomy on thymus age in mice. J Immunol 129(6): 2673-2677.

29. Ata Muradova F, Dontsov V (1987) Effect of transplantation of fetal hypothalamus in lymphoid tissue of old mice. Doklady Akademii nauk SSSR 297(1): 237-240.

30. Burnet F (1970) An immunological approach to ageing. Lancet 2(7668): 358-360.

31. Walford R (1969) The Immunological theory of aging. Copenhagen, Denmark.

32. Chizhov Y, Senchuk Y, Krutko V, Dontsov V (2013) The Application of the corrector of immune system Transfer factor for the decrease of human biological age. Technologii zhivyh system 10: 41-46.

33. Krut'ko V, Dontsov V, Khalyavkin A (2016) Effect of alphafetoprotein on lifespan of old mice. Biochemistry (Moscow). 81(12): 1477-1479.

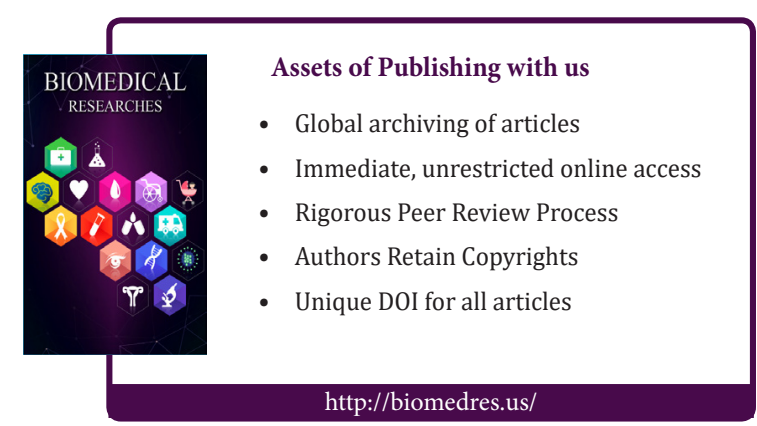

